\title{
Acute hemorrhagic edema of infancy: a worrisome presentation, but benign course
}

This article was published in the following Dove Press journal:

Clinical, Cosmetic and Investigational Dermatology

7 September 2013

Number of times this article has been viewed

\section{Ahmed H Alhammadi \\ Ashraf Adel \\ Mohamed A Hendaus \\ Department of Pediatrics, Section of General Pediatrics, Hamad Medical Corporation, Doha, Qatar}

Correspondence: Ahmed H Alhammadi Department of Pediatrics, Section of General Pediatrics, Hamad Medical Corporation, Doha, Qatar 3050

Tel +97444392239

Fax +974 4443 957।

Email aalhammadi@hmc.org.qa
Abstract: Acute hemorrhagic edema of infancy (AHEI) is a benign type of leukocytoclastic vasculitis. It is a benign phenomenon although it manifests with fever, large palpable purpuric skin lesions, and edema. The presentation of AHEI can often resemble that of HenochSchönlein purpura. Since AHEI is a self-limited disease, conservative management is the most commonly followed approach. Our patient had complete resolution of AHIE without medical treatment.

Keywords: infancy, hemorrhagic, edema

\section{Introduction}

Acute hemorrhagic edema of infancy (AHEI) is a benign type of leukocytoclastic vasculitis. It has also been described as Finkelstein's disease, Seidlmayer's disease, and postinfectious cockade purpura. ${ }^{1}$ AHEI is considered a benign phenomenon and it usually resolves spontaneously in a few weeks. ${ }^{2}$ We are presenting a 14 month old male with AHEI who presented with rash on the face and extremities, as well as edema in the left lower extremity.

\section{Case report}

A 14 month old boy presented to our emergency department with intermittent low grade fever of 2 days duration associated with a rash, swelling of the left leg, and an inability to bear weight. The mother stated that the patient had a runny nose and a mild cough 1 week prior to admission.

There was no diarrhea, change in behavior, toxic ingestion, medication use, or any recent vaccinations. Past medical history and family history were unremarkable and immunizations were up to date. The patient was admitted to the ward for fever and rash. On admission, his temperature was $38^{\circ} \mathrm{C}$, he had a respiratory rate of 25 breaths per minute, his heart rate was 110 beats per minute, and his blood pressure was 100/70 mmHg.

On examination, the patient was not looking toxic, his neck was supple, and the neurological exam was unremarkable. The skin showed ecchymotic, purpuric, targetoid plaques with oval and round shapes on the face and extremities (Figures 1-3). The right auricle of the ear was mildly edematous and purple in color. There was mild swelling on the hands and lower extremities without skin induration and the range of motion of all joints was normal. The rest of the physical exam was unremarkable. The complete blood count and urine analysis were both unremarkable. 


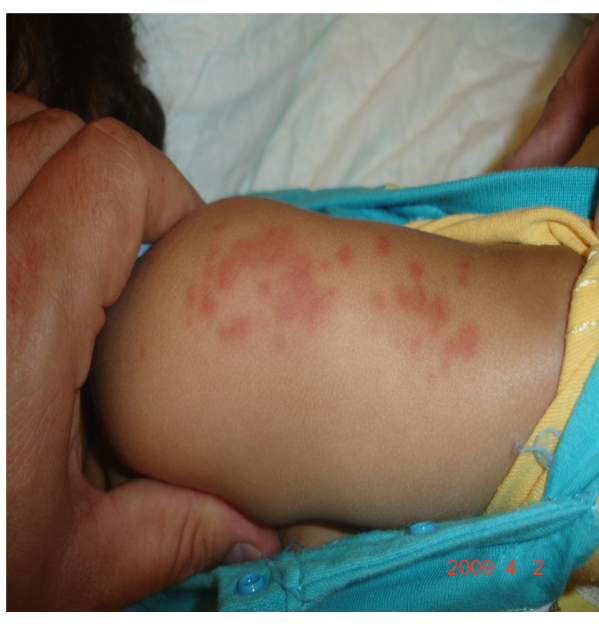

Figure I Purpuric and ecchymotic lesions on the left lower extremity.

A decision was made to biopsy one of the lesions from the left forearm and it showed inflammatory infiltrate surrounding dermal blood vessels. The infiltrate was a mixture of neutrophils, lymphocytes, and scattered eosinophils with fragmented nuclei of neutrophils, and there was focal necrosis of the vessel wall. On direct immunofluorescence there was no immunoglobulin A ( $\operatorname{Ig}$ A) deposition. The patient was discharged after the diagnosis and the rash resolved spontaneously in 3 weeks.

\section{Discussion}

AHEI is more common in males, ${ }^{2}$ without racial predominance. ${ }^{3}$ The age group is typically between 4 and 24 months. ${ }^{1}$ In the majority of the cases, AHEI is a selflimited disease (1-3 weeks), but there have been reports of recurrent attacks (up to four attacks). ${ }^{4}$

Patients with AHEI are usually nontoxic on presentation ${ }^{2}$ and they classically present with fever, large palpable purpuric

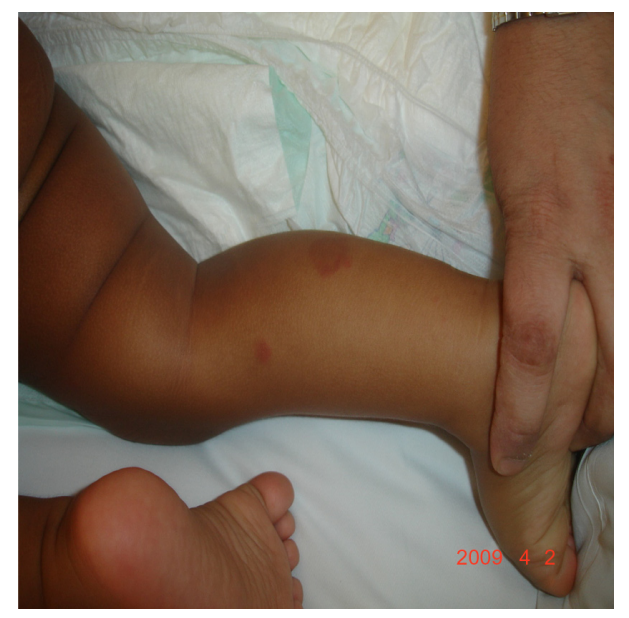

Figure 2 Oval, purpuric, and targetoid lesion on the right lower extremity. skin lesions, and edema. The skin changes are characterized as well demarcated, annular, medallion-like, rosette shaped purpuric plaques, and tend to appear suddenly in the face and extremities. ${ }^{1}$ However, the skin lesion does not always present in a typical way and it has been reported that it can appear as hemorrhagic blisters. ${ }^{3}$ The edema is typically on the face, extremities, and auricles. ${ }^{2}$

Many organisms including adenovirus, vermicelli zoster virus, cytomegalovirus, herpes simplex virus, tuberculosis, streptococci, and staphylococci are associated with AHEI. ${ }^{4}$ Almost $75 \%$ of cases of AHEI are preceded by infections like otitis media, urinary tract infection, upper respiratory infection, and pneumonia. An immune complex hypersensitivity complex has been suggested as the etiology of AHEI since vaccines and medications are trigger factors. ${ }^{2}$

Extracutaneous and viscera involvement are rare with AHEI. However, Fiore et al documented two cases with intestinal engagement ${ }^{5}$ and Wanatabe and Sato reported a case with renal involvement and hypocomplementemia. ${ }^{6}$

Blood laboratory results are usually nonspecific. In a complete blood count there might be thrombocytosis, leukocytosis with eosinophilia, or lymphocytosis. In addition, $\mathrm{C}$-reactive protein and the erythrocyte sedimentation rate may be high. ${ }^{7}$ In some cases, patients with AHEI can present with hypocomplementemia affecting complement $\mathrm{C} 4$, complement $\mathrm{C} 1 \mathrm{q}$, and complement $\mathrm{CH} 50,{ }^{8}$ and transient abnormal liver function. ${ }^{9}$

A skin biopsy for histopathology and immunofluorescence testing is useful if diagnosis is unclear. ${ }^{10}$ The typical description of the histology in the patient with AHEI is perivascular neutrophilic infiltration with several nuclear fragments in the vascular wall, resulting in fibrinoid necrosis. ${ }^{7}$ The rare serious complications of AHEI are renal involvement, gastrointestinal bleeding, epididymo-orchitis, and cartilage damage. ${ }^{11}$

Since AHEI is a self-limited disease, conservative management is the most commonly followed approach. ${ }^{2}$ Steroid use is warranted when there is a severe or persistent gastrointestinal symptom or complication of the disease. The use of immunosuppressive medications like cyclophosphamide or azathioprine to prevent renal damage has been reported as futile. ${ }^{10}$ Antibiotics can be used if there is a concomitant bacterial infection. $^{\text {? }}$

AHEI can present as erythema multiforme, but the latter does not show leukocytoclastic vasculitis. AHEI can also mimic urticarial vasculitis, but the former usually has an acute presentation with rare remissions. ${ }^{8}$ The presentation of AHEI can often resemble that of Henoch-Schönlein purpura (HSP) and some authors consider AHEI as a cutaneous 


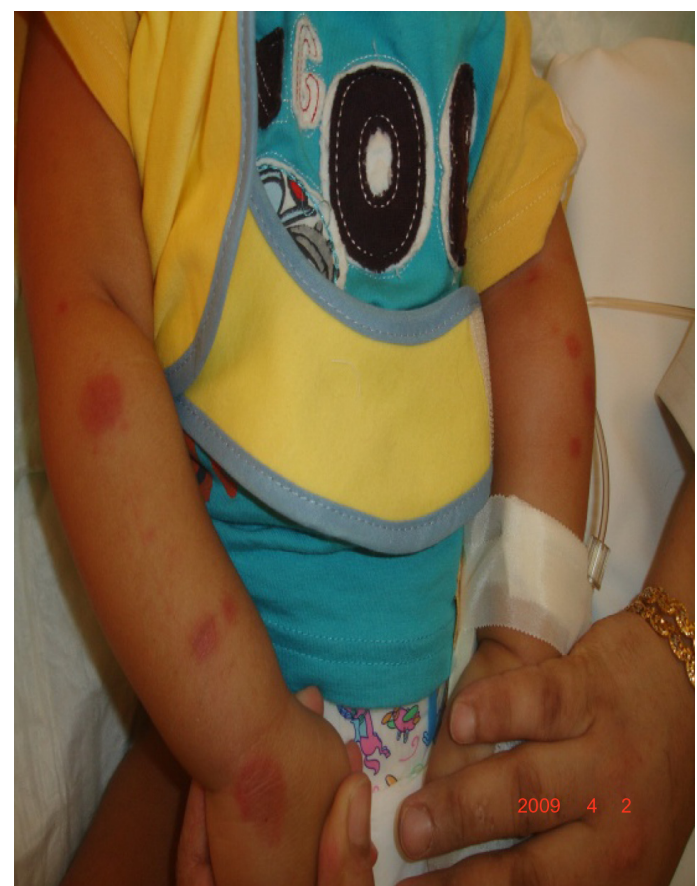

Figure 3 Circular and oval plagues on the upper extremities with swelling more prominent on the right side.

variant of HSP. ${ }^{1}$ It is crucial to differentiate between AHEI and HSP since the latter requires systemic corticosteroid therapy. AHEI and HSP are similar in that both have skin lesions and leukocytoclastic vasculitis. However, the differences are as follows. AHEI presents in a younger population ( 3 to 24 months old) in comparison to HSP (3 to 6 years old). ${ }^{11}$ The skin lesions in AHEI manifest as ecchymotic changes with large purpura and edema involving the face, extremities and scrotum, while the purpura in HSP is usually smaller and involves the buttocks and the legs. ${ }^{12}$ Involvement of renal, gastrointestinal, and viscera are rare in AHEI when compared to HSP. IgA levels are usually normal in AHEI, but elevated in HSP. ${ }^{11}$ There is usually no IgA deposition in AHEI compared to HSP. Finally, complement C1q deposition is more diagnostic of AHEI. ${ }^{2}$

\section{Conclusion}

AHEI is a self-limited disease that usually resolves spontaneously. It is crucial to make the diagnosis correctly to avoid unnecessary work up and therapy, while simultaneously monitoring for rare but severe complications.

\section{Disclosure}

The authors report no conflicts of interest in this work.

\section{References}

1. Jindal SR, Kura MM. Acute hemorrhagic edema of infancy-a rare entity. Indian Dermatol Online J. 2013;4(2):106-108.

2. Savino F, Lupica MM, Tarasco V, et al. Acute hemorrhagic edema of infancy: a troubling cutaneous presentation with a self-limiting course. Pediatr Dermatol. [Epub ahead of print].

3. Karremann M, Jordan AJ, Bell N, Witsch M, Dürken M. Acute hemorrhagic edema of infancy: report of 4 cases and review of the current literature. Clin Pediatr (Phila). 2009;48(3):323-326.

4. Fotis L, Nikorelou S, Lariou MS, Delis D, Stamoyannou L. Acute hemorrhagic edema of infancy: a frightening but benign disease. Clin Pediatr (Phila). 2012;51(4):391-393.

5. Fiore E, Rizzi M, Ragazzi M, et al. Acute hemorrhagic edema of young children (cockade purpura and edema): a case series and systematic review. J Am Acad Dermatol. 2008;59:684-695.

6. Watanabe T, Sato Y. Renal involvement and hypocomplementemia in a patient with acute hemorrhagic edema of infancy. Pediatr Nephrol. 2007;22:1979-1981.

7. Freitas $P$, Bygum A. Visual impairment caused by periorbital edema in an infant with acute hemorrhagic edema of infancy. Pediatr Dermatol. [Epub ahead of print].

8. Bansal S, Ghate S, Jerajani HR. Sudden onset purpura in a healthy infant: acute hemorrhagic edema of infancy. Indian J Dermatol. 2011;56(3): 349-351.

9. Obeid M, Haley J, Crews J, Parhizgar R, Johnson L, Camp T. Acute hemorrhagic edema of infancy with abdominal pain and elevated transaminases. Pediatr Dermatol. 2008;25(6):640-641.

10. Yu JE, Mancini AJ, Miller ML. Intussusception in an Infant with acute hemorrhagic edema of infancy. Pediatr Dermatol. 2007;24:61-64.

11. Moradinejad MH, Entezari P, Mahjoub F, Ziaee V. Acute hemorrhagic edema of infancy; a report of five Iranian infants and review of the literature. Iran J Pediatr. 2011;21(1):107-112.

12. Javidi Z, Maleki M, Mashayekhi V, Tayebi-Maybodi N, Nahidi Y. Acute hemorrhagic edema of infancy. Arch Iran Med. 2008;11(1):103-106.
Clinical, Cosmetic and Investigational Dermatology

\section{Publish your work in this journal}

Clinical, Cosmetic and Investigational Dermatology is an international, peer-reviewed, open access, online journal that focuses on the latest clinical and experimental research in all aspects of skin disease and cosmetic interventions. All areas of dermatology will be covered; contributions will be welcomed from all clinicians and

\section{Dovepress}

basic science researchers globally. This journal is indexed on CAS The manuscript management system is completely online and includes a very quick and fair peer-review system, which is all easy to use. Visit http://www.dovepress.com/testimonials.php to read real quotes from published authors. 